\title{
Flow Chronopotentiometry with Ion-Selective Membranes for Cation, Anion and Polyion Detection
}

Majid Ghahraman Afshar, Gastón A. Crespo, and Eric Bakker*

Department of Inorganic and Analytical Chemistry, University of Geneva, Quai Ernest-Ansermet 30, CH1211 Geneva, Switzerland.

Corresponding Author: eric.bakker@unige.ch; 

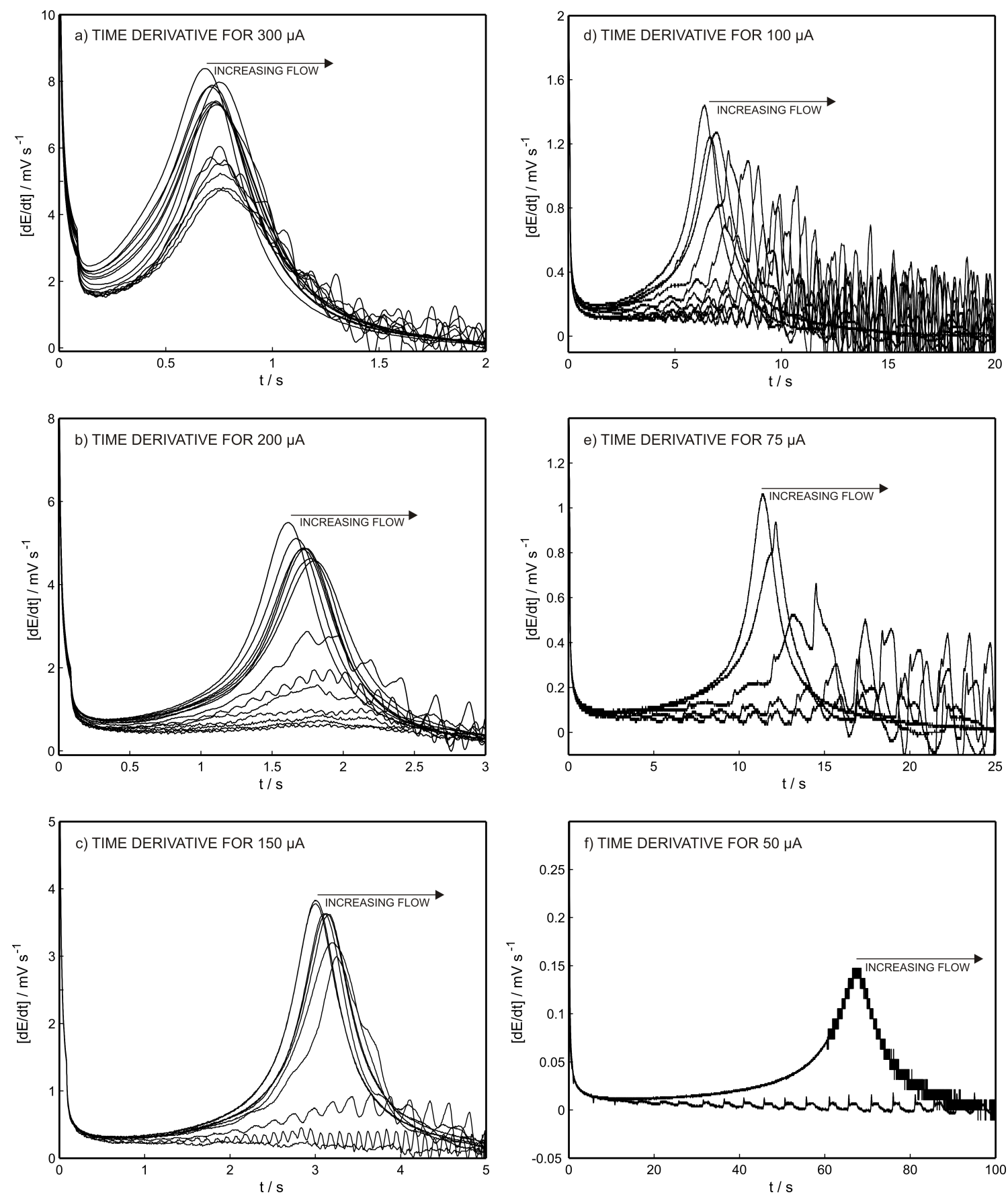

Figure S1. Chronopotentiometric time derivatives in contact with a sample containing $0.3 \mathrm{mM}$ of sodium chloride at different flow rates (from 0.5 to $10 \mathrm{ml} \mathrm{min}^{-1}$ ) and applied currents. a) $300 \mu \mathrm{A}$, b) $200 \mu \mathrm{A}, \mathrm{c}$ ) $150 \mu \mathrm{A}$, d) $100 \mu \mathrm{A}$, e) $75 \mu \mathrm{A}$, f) $50 \mu \mathrm{A}$. Membrane as for Figure 2; background electrolyte: $10 \mathrm{mM} \mathrm{NaF}$. 


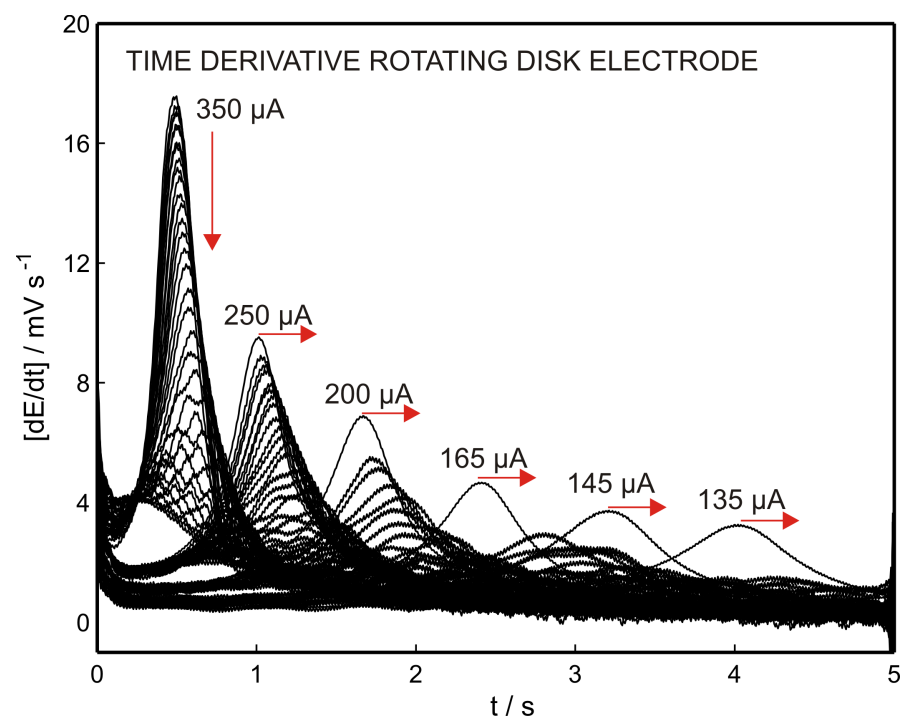

Figure S2. Chronopotentiometric time derivatives in contact with a sample solution containing $0.1 \mathrm{mM}$ sodium chloride as function of rotation speed (from 100 to $600 \mathrm{rpm}$ ). Red arrows indicate the increase of rotation speed for each current pulse. Membrane as for Figure 2; background electrolyte: $10 \mathrm{mM} \mathrm{NaF}$. 


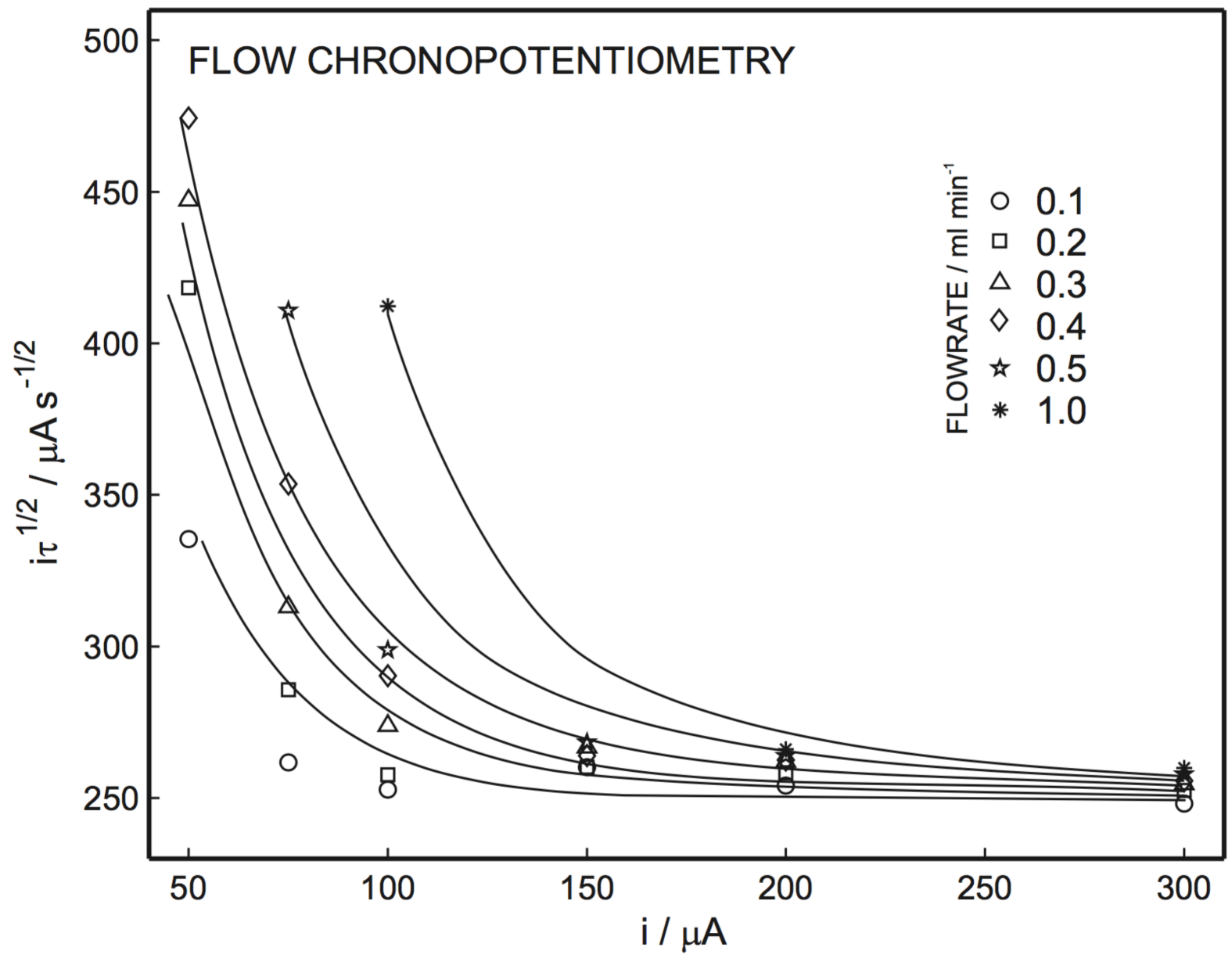

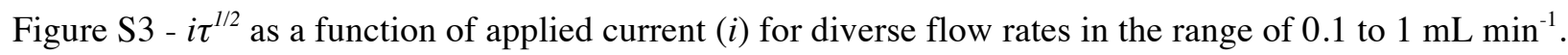
Membrane as for Figure 2; background electrolyte: $10 \mathrm{mM} \mathrm{NaF}$. 


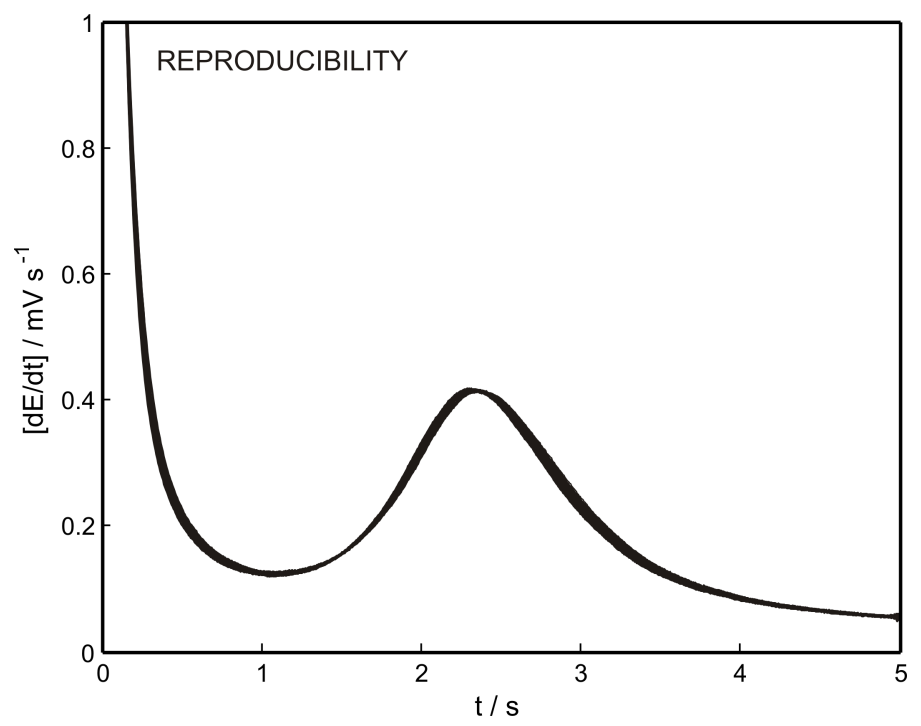

Figure S4 - Reproducibility of protamine detection for 30 measurements using the same membrane. Protamine concentration of $100 \mathrm{ppm}$ in a $0.1 \mathrm{M} \mathrm{NaCl}$ background electrolyte. 